\title{
FEMALE UROLOGY
}

\author{
The urologist's guide to genital piercing \\ Anderson WR, Summerton DJ, Sharma DM, Holmes SA \\ Solent Department of Urology, St. Mary's Hospital, Portsmouth, UK \\ BJU Int. 2003, 91:245-51
}

Over the past 10 years or so, there has been a clear increase in the number of people practicing body piercing, in particular, many young people appear keen to adopt an individuality with the 'body art', which they may regard as an expression of identity. It is perhaps ironic that this perceived individuality is in fact shared with thousands of others.

No part of the human anatomy is apparently immune from this fashion, but an examination into the history of body piercing reveals that such decoration s are far from being an invention of the late 20th century. Indeed, as discussed in this review, piercing has occurred for thousands of years, in societies throughout the world, and has been adopted through the spectrum of social class.

Urologists should perhaps be particularly aware of the seemingly bizarre practice of genital piercing, as their specialist knowledge may sometimes be required to manage the inevitable complications.

\section{Editorial Comment}

This guide covers both male and female piercing. The authors describe genital piercing with regards to: historical aspects; current laws; techniques of placement; and categorization of the types of genital piercings. In addition, there is an excellent section on potential urologic complications.

The urologist is expected to understand and treat maladies both spontaneous and self-inflicted from all walks of life. Besides tattooing, no other form of body adornment has separated the young from the old than body piercing and particularly genital piercing. Nevertheless, even if the mature urologist never grew up in a time where male and females pierced and tattooed various areas of their bodies with a remarkable frequency, he is expected to be able to look at a piercing, understand the potential urological complications and technique that it required. This paper helps the urologist with these specific tasks.

Interest in piercing of the genitals has risen to a point where some may consider it an art form as opposed to an attraction of a salacious or prurient nature. For those members of society who wishes not to pierce their genitals or body there is deep lack of understanding of those who choose to pierce. Perhaps it is an attempt by those who subject themselves to piercing to obtain a more protean state than that which they acquired through the form of genetics sweepstakes from their parents and thus the incidence of piercing has raised to the point where it is now considered not outside of the standard state of propriety. 
I recommend this article as part of one's reference library in the office. There are few places where one may obtain such a guide in a succinct and efficient manner with an amazing amount of clarity and marvelous pictures to which future reference may be obtained. Simply put: read the article if only for the pictures.

\author{
Dr. Steven P. Petrou \\ Associate Professor of Urology \\ Mayo Medical School \\ Jacksonville, Florida, USA
}

\title{
Incontinent ileovesicostomy in the management of neurogenic bladder dysfunction \\ Gauthier Jr. AR, Winters JC \\ Department of Urology, Ochsner Clinic Foundation, New Orleans, Louisiana \\ Neurourol Urodyn. 2003; 22:142-6
}

Aims: To report outcome and urodynamic follow-up of incontinent ileovesicostomy in quadriplegic patients with neurogenic bladder.

Methods: Seven patients (five male, two female, mean age $33.7 \mathrm{yr}$ ) with neurogenic bladder underwent ileovesicostomy for management of leakage or complications of chronic catheter drainage. Five had chronic indwelling catheters: three suprapubic and two urethral. Preoperatively, all had upper tract evaluation and videourodynamics. All seven patients had detrusor hyperreflexia. Preoperative detrusor leak point pressures averaged $42.7 \mathrm{~cm} \mathrm{H}_{2} \mathrm{O}$. Two females had intrinsic sphincteric deficiency from prolonged Foley catheter drainage. Ileovesicostomy involves isolation of a $15-20 \mathrm{~cm}$ segment of terminal ileum. The proximal $6-8 \mathrm{~cm}$ of this segment is opened on the antimesenteric border. The dome of the bladder is opened widely in a transverse manner and the proximal portion of the bowel is sutured onto the bladder. The distal portion of the ileum remains tabularized and becomes the stoma.

Results: There were no intraoperative complications. Operative time averaged 159 minutes. Associated procedures included removal of bladder calculus $(n=1)$, pubovaginal sling $(n=2)$, and Marshall Marchetti Krantz suspension $(\mathrm{n}=1)$. Mean blood loss was $<200 \mathrm{cc}$ in six patients. Mean hospital stay was 8 days. Complications in two patients included: fascial stenosis requiring stoma revision $(\mathrm{n}=1)$, wound infection $(\mathrm{n}=$ $1)$, and postoperative ileus $(\mathrm{n}=1)$. Mean follow-up was 37.4 months. Postoperatively, mean detrusor leak point pressures were $16.7 \mathrm{~cm} \mathrm{H}_{2} \mathrm{O}(\mathrm{P}=0.0061)$. Patient satisfaction is high with only one complaint of occasional difficulty fitting the appliance.

Conclusions: Ileovesicostomy is an effective method of urinary drainage in quadriplegic patients. Detrusor leak point pressures were lowered, and upper tracts were preserved. No long-term complications encountered.

\section{Editorial Comment}

The authors present their experience in patients with detrusor hyperreflexia refractory to medical therapy or unable to perform CIC who then underwent an incontinent ileovesicostomy. Preoperatively, urodynamics were completed on all patients with average detrusor leak point pressures being $42.7 \mathrm{~cm}_{2} \mathrm{O}$. Patients with arreflexic/poorly contracting bladders were not offered the procedure. During the surgical case, a $15-20 \mathrm{~cm}$ section of terminal ileum was isolated with the proximal 6-9 $\mathrm{cm}$ of this segment being opened on the anti-mesenteric border and used as an augmentation to the bladder. Postoperatively, no bladder catheters were used and the ileostomy segment was stented with a red rubber catheter. Mean follow-up was 37.4 months. Complications occurred in 4 of 7 patients including fascial stenosis requiring stomal revision in one patient. 
This is a very good and succinct paper that reminds one of the importance of this operation for all patients including female patients who have neurogenic vesical dysfunction and are unresponsive or unable to comply with the regimen of anticholinergic therapy and clean intermittent catheterization. As highlighted by the authors the main advantages of this procedure were preservation of the native ureterovesical junction and avoidance of a dysfunctionalized bladder. Though a passive drainage system similar to a cutaneous vesicostomy, previous authors have highlighted that vesicostomy in adults has only had mixed success (1). The attractiveness of this surgery includes that of removing the often used suprapubic tube and its secondary associated bladder irritation, and potential hematuria. This paper is very well written though it would have been of interest if the authors had expounded on the incidence of autonomic dysreflexia in their patients pre- and postoperatively. In addition, if the reader is interested, there are several other excellent papers on this operation and its treatment of this difficult clinical malady (1,2). These include reports from Dr. McGuire's group including one from 1994, which has good explanatory diagrams of the operation and the follow-up paper 5 years later, which provides excellent long term outcome results from this surgery $(1,2)$. Of note is that in those authors' hands and in this paper's report, fascial and stomal stenosis mirrored that of the ileal conduit urinary diversion. Both female patients in this study group underwent pubovaginal slings. Previous authors have based their placement of slings on urodynamics with sling being offered for proximal urethral dysfunction and formal bladder outlet closure for a non-salvageable situation (2). Should consideration be given to a suburethral sling or urethropexy in all females undergoing the reconstruction regardless of their urethral support or intrinsic sphincter function? In addition, this paper, as have others $(1,2)$, highlight the need for early postoperative urodynamics to establish operative success in the form of acceptable detrusor leak point pressures. The reader should remind himself of the difference between a Valsalva leak point pressure and a detrusor leak point pressure (3). The authors do elude peripherally in their discussion on the use of ileovesicostomy in patients with hypocontractile bladders. Future elucidation or quantification on the minimal detrusor strength required to be a candidate for this operation will be of great interest. In addition, I hope in the future we will be privileged to read the authors' reports on the use of incontinent ileovesicostomy in patients with hypocontractile bladders if the clinical series is developed.

\section{References}

1. Schwartz SL, Kennelly MJ, McGuire EJ, Faerber GJ: Incontinent ileovesicostomy urinary diversion in the treatment of lower urinary tract dysfunction. J Urol. 1994; 152:99-102.

2. Leng WW, Faerber G, Del Terzo M, McGuire EJ: Long-term outcome of incontinent ileovesicostomy management of severe lower urinary tract dysfunction. J Urol. 1999; 161:1803-6.

3. Wan J, McGuire EJ, Bloom DA, Ritchey ML: Stress leak point pressure: a diagnostic tool for incontinent children. J Urol. 1993; 150:700-2.

Dr. Steven P. Petrou Associate Professor of Urology Mayo Medical School Jacksonville, Florida, USA 